\title{
PROJETO DE EXTENSÃO ESPORTIVO DE BASQUETEBOL EM CONTEXTO ESCOLAR: PERCEPÇÕES DOS TREINADORES
}

\section{EXTENSION PROJECT WITH BASKETBALL IN SCHOOL CONTEXT: COACHES' PERCEPTIONS}

\author{
Jaqueline da Silva* \\ ORCID: https://orcid.org/0000-0002-5248-3679 \\ Kauana Possamai** \\ ORCID: https://orcid.org/0000-0002-5643-4559 \\ Cristiano Zarbato Morais*** \\ ORCID: https://orcid.org/0000-0001-8535-1819 \\ Ahlan Benezar Lima**** \\ ORCID: https://orcid.org/0000-0001-8691-5719 \\ Vinícius Plentz de Oliveira***** \\ ORCID: https://orcid.org/0000-0002-4767-3398 \\ Humberto Jorge Gonçalves Moreira de Carvalho****** \\ ORCID: https://orcid.org/0000-0002-2855-0296
}

Data recebimento: 07/09/2020

Data de aceite: 03/03/2021

\section{Resumo}

Objetivou-se relatar as percepções dos treinadores, autores deste relato, sobre a implementação do projeto de extensão Centro de Formação no Treino de Basquetebol (CFTB) em um contexto escolar. O projeto é uma parceria entre a Universidade Federal de Santa Catarina (UFSC) e a Federação Catarinense de Basketball (FCB). Caracterizado como qualitativo, descritivo, este estudo configura-se como um relato de experiência. Como resultados, destacam-se: a infraestrutura da escola suficiente para a realização do projeto; o relacionamento positivo com os jovens; a aproximação entre teoria e prática e a facilidade da localização próxima da escola com a universidade. Dentre as dificuldades: os dias de chuva que causam goteiras na quadra, o tamanho inadequado das tabelas para a categoria sub 12 e a sobrecarga acadêmica dos treinadores. Conclui-se que a participação dos treinadores, apesar das dificuldades apontadas, tem contribuído de forma significativa para a formação profissional.

Palavras-chave: Projeto de extensão; Basquetebol; Treinadores; Escola; Percepções.

\begin{abstract}
The aim of the study was to report the perceptions of the coaches, authors of this report, about the implementation of the extension project of the Basketball Training Center (CFTB) in a school context. The project is a partnership between the Federal University of Santa Catarina (UFSC) and the Santa Catarina Federation of Basketball (FCB). This is a qualitative and descriptive study configured as an experience report. The results show that the infrastructure of the school is sufficient to carry out the project; a positive relationship with young athletes has been developed; the approximation between theory and practice and the convenience of the location, since the school is close to the university. The difficulties found were: the rainy days that cause leaks on the court, the unsuitable size of the backboards for the under 12 category, and the academic overload of the coaches. Our results led to the conclusion that the participation of coaches, despite the difficulties pointed out, has contributed significantly to the professional development of training.
\end{abstract}

Keywords: Extension project; Basketball; Coaches; School; Perceptions.

* Aluna de Mestrado da Universidade Federal de Santa Catarina (UFSC), Florianópolis - SC, Brasil. E-mail. jaquelineds913@gmail.com ** Aluna de Graduação da Universidade Federal de Santa Catarina (UFSC), Florianópolis - SC, Brasil. E-mail. kauanapossamai@hotmail.com *** Aluno de Graduação da Universidade Federal de Santa Catarina (UFSC), Florianópolis - SC, Brasil. E-mail. cristianozm1997@gmail.com **** Aluno de Mestrado da Universidade Federal de Santa Catarina (UFSC), Florianópolis - SC, Brasil. E-mail. allanbenezar@gmail.com ***** Aluno de Mestrado da Universidade Federal de Santa Catarina (UFSC), Florianópolis - SC, Brasil. E-mail. viniciusplentz19@gmail.com ****** Professor da Universidade Federal de Santa Catarina (UFSC), Florianópolis - SC, Brasil. E-mail. hmoreiracarvalho@gmail.com 


\section{Introdução}

A educação superior no Brasil, por meio das universidades, tem como função primária formar profissionais nas diferentes áreas do conhecimento e fomentar a pesquisa e investigação científica (BRASIL, 2016). Porém, de que serve o conhecimento se ele não atravessa os muros das instituições de ensino? Através da Lei de Diretrizes e Bases da Educação Nacional (capítulo IV, artigo 43), a universidade passa a ter o papel de externalização do conhecimento e prestação de serviços à comunidade, o que, na maioria dos casos, acontece por meio de projetos de extensão (DESLANDES; ARANTES, 2017).

Assim como em projetos promovidos por organizações privadas e de terceiro setor, os projetos de cunho social e com origem em instituições públicas têm uma preferência por políticas esportivas (SILVA, 2014). Neste sentido, na contemporaneidade, o esporte tem se apresentado como fenômeno sociocultural (MACHADO et al., 2015), tanto do ponto de vista do espetáculo quanto como atividade comercial e profissional, assumindo nos últimos anos um papel de importância na economia (RUBIO, 2006), até então de acesso restrito e atualmente sendo de amplo acesso a todos (GALATTI, 2010).

Desta forma, o esporte pode atingir as pessoas de diferentes maneiras e alcançar diferentes objetivos, como na saúde, estética, lazer, socialização e educação (GALATTI, 2010). Consequentemente, fomentando benefícios técnicos, táticos, físicos, psicológico e sociais, promovendo um ambiente de diversificação, inclusão, cooperação e autonomia (PAES; BALBINO, 2005). Corrobora Côté (2013) ao relatar que atividades e programas esportivos desempenham importante papel na vida dos praticantes, fornecem aos jovens oportunidades de serem fisicamente ativos, promovem aprendizagem de habilidades motoras, bem como atitudes como a cooperação, a disciplina, a liderança e controle de si mesmo. Dória e Tubino (2006) ainda destacam que atividades esportivas facilitam o desenvolvimento da sociabilidade e das relações interpessoais, além de preencher o tempo ocioso, o que apresenta ainda mais importância quando relacionado a crianças e adolescentes em vulnerabilidade social.

Dentre as diversas modalidades esportivas que auxiliam no desenvolvimento de jovens, destaca-se o basquetebol, modalidade que desde 1936 faz parte do quadro olímpico. Originou-se nos Estados Unidos no final do século XIX, com o intuito de propiciar a prática de atividade física durante o período de inverno. Rapidamente, disseminou-se entres os países e, atualmente, segundo Galatti et al. (2012), está entre as modalidades mais praticadas no mundo, tendo mais de 300 milhões de praticantes e 215 países filiados à Federação Internacional de Basquetebol (Fiba).

Assim, a escolha por este esporte deu-se pelo fato de que, no contexto universitário do qual fazem parte os autores deste relato, vem sendo desenvolvido um projeto de extensão cujo objetivo é a formação no treino de basquetebol através da iniciação esportiva. Tendo em vista os benefícios da prática esportiva, bem como os feedbacks positivos dos integrantes do projeto no contexto universitário, percebeu-se a necessidade de implementar o projeto em um contexto escolar, visando oportunizar a crianças e jovens tempo e espaço para experiências a que não teriam por outro meio. 
Ressalta-se, ainda, que o projeto, inserido na escola, encontra-se fundamentado no Desenvolvimento Positivo de Jovens (DPJ), o qual busca desenvolver habilidades para além dos esportes, potencializando características positivas, atitudes e valores para a vida em sociedade (DAMON, 2004). Segundo Gaion et al. (2020), os projetos de extensão são uma das maneiras possíveis de potencializar o DPJ na realidade brasileira. Contudo, poucos estudos são encontrados que abordam e relatam projetos de extensão, principalmente os de cunho esportivo. Diante do exposto, o objetivo deste estudo é relatar as percepções dos treinadores, autores deste relato, sobre a implementação de um projeto de extensão universitária de iniciação esportiva ao basquetebol em um contexto escolar. Para tanto, este estudo qualitativo e de caráter descritivo (DENZIN; LINCOLN, 2006) configura-se como um relato de experiência narrado justamente por educadores envolvidos no processo de desenvolvimento do planejamento, da implementação e avaliação de todo o caminho percorrido (NEIRA, 2017).

\section{O projeto: Centro de Formação no Treino de Basquetebol (CFTB)}

O projeto de extensão esportivo intitulado Centro de Formação no Treino de Basquetebol (CFTB) foi criado em fevereiro de 2018 com o objetivo de promover um contexto de formação esportiva de jovens no Basquetebol, integrado ao desenvolvimento de jovens atletas e de contextos de aprendizagem para alunos de ensino superior no âmbito de sua formação profissional. O CFTB é fruto da Academia Catarinense de Basquetebol que, por sua vez, é uma parceria formal entre a Universidade Federal de Santa Catarina (UFSC) com a Federação Catarinense de Basketball (FCB) para desenvolvimento de atletas, professores, treinadores e demais profissionais ligados ao basquete, além da pesquisa científica.

O projeto de extensão universitário insere-se na respectiva universidade, contemplando 35 jovens e 37 adultos universitários, e, também, em uma escola pública localizada próxima da mesma, na qual 72 crianças são atendidas. Assim, o projeto oferece espaço e condições para a formação e o desenvolvimento de atletas de todos os níveis e idades, desde a iniciação esportiva ao alto rendimento, da segunda infância à idade adulta. Desta forma, os atletas podem estar engajados no ambiente de treino de basquetebol a partir das idades escolares iniciais à vida universitária.

Além da formação de atletas, o projeto também oferece espaço para a formação de novos profissionais que atuam com o esporte (treinadores, preparadores físicos, gestores, nutricionistas, setor jurídico, publicidade e marketing). Todas as ações são baseadas e argumentadas fundamentalmente pela produção intelectual do Núcleo de Pesquisa em Pedagogia do Esporte (NUPPE), que, por sua vez, intervém no projeto com ações práticas e de integração do ambiente esportivo com o acadêmico.

Semanalmente, às quintas-feiras, são realizadas reuniões para discutir sobre o desenvolvimento do projeto, organização de atividades e festivais, bem como debater sobre artigos relacionados à área do basquetebol. Nessas reuniões, comparecem os membros do 
projeto, que estruturam, planejam e implementam as atividades do basquetebol e outras demandas relacionadas ao projeto. Participam estudantes da graduação ( 9 acadêmicos) e PósGraduação (6 acadêmicos) em Educação Física, totalizando 15 membros, coordenados por um professor universitário que atua na graduação e pós-graduação.

Especificamente na implementação do projeto na escola atuam 9 estudantes, como treinadores, destes, 5 correspondem aos autores deste relato de experiência, os quais descreveram suas percepções relacionadas à implementação do projeto em um contexto escolar. No que tange ao perfil destes treinadores inseridos na escola, encontra-se, no Quadro 1, a formação, a experiência prévia com o basquetebol e o motivo pelo qual fazem parte deste projeto de extensão esportivo.

Quadro 1 - Informações dos Treinadores

\begin{tabular}{|c|c|c|c|c|c|}
\hline & & $\begin{array}{l}\text { Sexo e } \\
\text { Idade }\end{array}$ & Formação & $\begin{array}{c}\text { Experiência com } \\
\text { o basquetebol }\end{array}$ & $\begin{array}{c}\text { Motivo pelo qual participa do } \\
\text { projeto }\end{array}$ \\
\hline \multirow{5}{*}{$\begin{array}{l}\mathrm{T} \\
\mathrm{R} \\
\mathrm{E} \\
\mathrm{I} \\
\mathrm{N} \\
\mathrm{A} \\
\mathrm{D} \\
\mathrm{O} \\
\mathrm{R} \\
\mathrm{E} \\
\mathrm{S}\end{array}$} & 1 & $\begin{array}{l}M \\
22\end{array}$ & $\begin{array}{l}\text { Mestrando em } \\
\text { Educação Física }\end{array}$ & $\begin{array}{l}\text { Pratica a modalidade } \\
\text { recreacionalmente há quase } 10 \text { anos, } \\
\text { tendo experiência com o ensino do } \\
\text { basquetebol há } 2 \text { anos. }\end{array}$ & $\begin{array}{l}\text { Paixão pelo esporte e desejo de } \\
\text { proporcionar uma prática esportiva } \\
\text { organizada para jovens em contexto } \\
\text { escolar. }\end{array}$ \\
\hline & 2 & $\begin{array}{l}M \\
22\end{array}$ & $\begin{array}{l}\text { Graduando em } \\
\text { Educação Física }\end{array}$ & $\begin{array}{l}\text { Obteve o primeiro contato com o } \\
\text { esporte durante a graduação e atua } \\
\text { com o ensino do basquetebol há } 2 \\
\text { anos. }\end{array}$ & $\begin{array}{l}\text { Gosto pela modalidade, } \\
\text { identificação com os jovens } \\
\text { participantes do projeto e o } \\
\text { propósito de seguir na área. }\end{array}$ \\
\hline & 3 & $\begin{array}{l}M \\
25\end{array}$ & $\begin{array}{l}\text { Mestrando em } \\
\text { Educação Física }\end{array}$ & $\begin{array}{c}\text { Foi atleta da modalidade por } 13 \\
\text { anos e atualmente é árbitro da } \\
\text { Federação Catarinense de Basquete } \\
\text { (FCB). }\end{array}$ & $\begin{array}{c}\text { Ter o contato com a modalidade e } \\
\text { interesse de atuação com as } \\
\text { crianças na faixa etária do } \\
\text { projeto. }\end{array}$ \\
\hline & 4 & $\begin{array}{l}\mathrm{F} \\
23\end{array}$ & $\begin{array}{l}\text { Graduanda em } \\
\text { Educação Física }\end{array}$ & $\begin{array}{l}\text { Atuou como atleta por } 12 \text { anos e } \\
\text { atualmente é árbitra da Federação } \\
\text { Catarinense de Basquete (FCB). }\end{array}$ & $\begin{array}{c}\text { Identificação com o projeto e com a } \\
\text { modalidade e aspiração de } \\
\text { experimentar a atuação como } \\
\text { treinadora. }\end{array}$ \\
\hline & 5 & $\begin{array}{l}\mathrm{F} \\
28\end{array}$ & $\begin{array}{l}\text { Mestranda em } \\
\text { Educação Física }\end{array}$ & $\begin{array}{c}\text { Atuou } 14 \text { anos como atleta e } 3 \text { anos } \\
\text { como treinadora da modalidade nas } \\
\text { categorias de base, de } 9 \text { a } 12 \text { anos de } \\
\text { idade. }\end{array}$ & $\begin{array}{l}\text { Gosto pela modalidade e interesse } \\
\text { de se manter conectada ao contexto } \\
\text { escolar e com jovens estudantes. }\end{array}$ \\
\hline
\end{tabular}

Fonte: Elaborado pelos autores (2020). 


\section{O contexto da experiência}

Criada em 1963, a escola fica localizada na cidade de Florianópolis, SC, e atende pouco mais de 500 alunos, matriculados do primeiro ao nono ano do ensino fundamental. Conta com boa estrutura para o seu funcionamento, sendo 10 salas de aula, sala informatizada, biblioteca, auditório, laboratório de ciências, ginásio de esportes, sala para o curso de robótica, cozinha e depósito, refeitório, almoxarifado, banheiros para os estudantes, banheiro adaptado e depósitos, além de uma quadra externa, que está interditada no momento. Grande parte dos alunos reside no bairro próximo à escola, e, de acordo com Pinto e Colombi $(2013, \mathrm{p} .11)$,

No bairro convivem diversas realidades, condições desiguais de acesso a bens culturais
e sociais. Uma avenida movimentada corta a comunidade, oferecendo poluição e
perigos aos transeuntes, entre eles as crianças que diariamente fazem dela seu caminho
entre casa e escola. As calçadas esburacadas e pequenas colocam muitas vezes crianças,
bicicletas e carros no mesmo espaço. Os investimentos em boas instalações
administrativas para prefeitura contrastam com a precária situação de escolas,
bibliotecas, praças de lazer, postos de saúde nos bairros onde a população que paga
seus impostos vive. Neste contexto, ganha força a economia informal ou ainda, ações
ilegais como o crime, o tráfico ou a prostituição, onde alguns jovens passam a atuar em
busca de uma identidade e um projeto de vida.

Situada próxima à UFSC, a escola recebe durante o ano diversas atividades vinculadas aos cursos de licenciatura na área da música, artes visuais, jornalismo, além do Programa Institucional de Bolsa de Iniciação à Docência (PIBID) junto à UFSC e à Universidade do Estado de Santa Catarina (UDESC). Atualmente, o lema da escola é: Uma escola de leitores, escritores, artistas e desportistas.

\section{Desenvolvimento do ensino do basquetebol na escola}

O projeto de extensão de iniciação esportiva ao basquetebol inserido na escola está fundamentado na Teoria do Desenvolvimento Positivo de Jovens (DPJ). O DPJ prioriza as características positivas, as potencialidades que oferecem um futuro melhor aos jovens, prevenindo-os de fatores de risco, como falta de suporte familiar, baixo rendimento escolar ou baixa autoestima (ESPERANÇA et al., 2018). Além disso, o DPJ concentra-se individualmente em cada jovem, nos seus pontos fortes, interesses e potenciais futuros, não nas suas supostas incapacidades (DAMON, 2004). Desta maneira, busca-se desenvolver não apenas habilidades esportivas, mas também habilidades para a vida em sociedade.

Com relação aos treinamentos, o projeto é organizado da seguinte forma na escola: segundas e quintas-feiras - treino da categoria sub 16 feminino (4 treinadores); terças e sextasfeiras - treino da categoria sub 16 masculino ( 2 treinadores); e às quartas-feiras - treino do sub 12 misto ( 3 treinadores). Todos os treinos são realizados às $17 \mathrm{~h} 15 \mathrm{~min}$ e finalizam às 
18h30min no ginásio esportivo da escola, com a utilização de materiais disponibilizados pela mesma e ainda complementados pelo projeto.

Inicialmente, para a implementação da proposta do ensino do basquetebol na escola, foram estabelecidos pelos treinadores os seguintes objetivos gerais: conhecer os estudantes; diagnosticar o nível de conhecimento dos mesmos sobre a modalidade do basquetebol; avaliar o nível das habilidades coordenativas e técnicas; construir e estabelecer relações positivas e de comprometimento com os estudantes; potencializar características positivas e atitudes para a vida em sociedade; e promover um ambiente de aprendizagem seguro e agradável para todos os envolvidos.

Relativamente a este processo, estabeleceu-se uma estruturação do treino, adotada por todos os treinadores inseridos na escola, descrita no Quadro 2, o qual expõe a divisão do treino em três partes (inicial, principal e final), e ainda o que cada parte deve contemplar para atingir os objetivos estabelecidos de determinado treino.

Quadro 2 - Estruturação do treino

\section{Parte inicial}

Reunir os participantes e expor o objetivo do treino. Realizar o aquecimento através de brincadeiras e jogos que contemplem um dos conteúdos do treino.

\section{Parte principal}

Realizar atividades, brincadeiras e exercícios visando a aprendizagem do conteúdo proposto no treino. Posteriormente, propor um dos jogos reduzidos do basquetebol, tais como: $2 \times 2,3 \times 2,3 \times 3,4 \times 4$ ou, ainda, o jogo de basquetebol propriamente dito, 5x5. Reforçar a importância da cooperação, respeito, diálogo e trabalho em grupo.

\section{Parte final}

Finalizar o treino com atividades lúdicas de arremesso ou atividades que visam a cooperação, a atenção e a concentração. Reunir os participantes e conversar sobre as percepções que tiveram do treino realizado, as dúvidas, as facilidades, as dificuldades e como superá-las.

Fonte: Elaborado pelos autores (2020)

Apesar de seguirem a mesma estrutura de treino, os treinadores de cada categoria selecionam, planejam e conduzem os conteúdos da modalidade de formas diferentes a partir dos achados da avaliação diagnóstica observadas em cada categoria. A avaliação diagnóstica geralmente ocorre antes de iniciar um conteúdo, fornecendo ao professor informações do estágio em que se encontram os jovens em determinado conteúdo (LUCKESI, 2009). A partir 
disso, os treinadores, separados por categoria, reúnem-se para planejar os objetivos, as atividades e as estratégias de ensino para os treinamentos de basquetebol na escola.

No que tange às ações propostas ao desenvolvimento do ensino do basquetebol com as categorias sub 12 misto, sub 16 masculino e feminino, encontram-se sintetizados no Quadro 3 os conteúdos, os objetivos, as estratégias utilizadas e, ainda, a duração dos treinamentos de cada categoria.

Quadro 3 - Conteúdos, objetivos de aprendizagem, estratégias de ensino e duração

\begin{tabular}{|c|c|c|}
\hline Categorias & Conteúdos & Estratégias/Duração \\
\hline $\begin{array}{l}\text { Sub12 } \\
\text { Misto }\end{array}$ & $\begin{array}{c}\text { Jogos e Brincadeiras; Passe; Drible; } \\
\text { Arremesso. Atitudes e valores como: empatia, } \\
\text { respeito e liderança. }\end{array}$ & $\begin{array}{l}\text { Progressão de exercícios; } \\
\text { Jogos reduzidos e recreativos; } \\
\quad 4 \text { meses de duração; }\end{array}$ \\
\hline $\begin{array}{c}\text { Sub16 } \\
\text { Masculino }\end{array}$ & $\begin{array}{l}\text { Escola de Corrida; Superação do Jogo } \\
\text { Anárquico; Manejo de Bola; Drible; Passe; } \\
\text { Bandeja; Arremesso. Atitudes e valores como: } \\
\text { cooperação, respeito e liderança. }\end{array}$ & $\begin{array}{c}\text { Progressão de exercícios; } \\
\text { Jogos reduzidos, recreativos e formal; } \\
\text { Série de Jogos; } \\
7 \text { meses de duração. }\end{array}$ \\
\hline $\begin{array}{c}\text { Sub16 } \\
\text { Feminino }\end{array}$ & $\begin{array}{l}\text { Controle de Corpo; Escola de Corrida; } \\
\text { Superação do Jogo Anárquico; Manejo de } \\
\text { Bola; Drible; Passe; Bandeja; Arremesso; } \\
\text { Transição; Defesa; 1x1. Atitudes e valores } \\
\text { como: trabalho em equipe, diálogo, respeito, } \\
\text { liderança e zelo pelo ambiente. }\end{array}$ & $\begin{array}{l}\text { Progressão de exercícios; } \\
\text { Jogos reduzidos, recreativos e formal; } \\
\text { Série de jogos; } \\
7 \text { meses de duração. }\end{array}$ \\
\hline
\end{tabular}

Fonte: Elaborado pelos autores (2020)

Dentre as estratégias utilizadas, as mais citadas pelos treinadores são: progressão de exercícios, jogos reduzidos e recreativos. A progressão de exercícios ocorre por meio de exercícios com habilidades simples ou combinadas, com/sem oposição, que se caracterizam como tarefas sistematizadas, com duração breve, em que há o isolamento de uma ou mais habilidades motoras do contexto do jogo e que podem envolver ou não contato com adversário (RINK, 1993). Os jogos reduzidos são aqueles em que ocorre a diminuição e/ou modificação dos espaços ou número de jogadores, a fim de reduzir a complexidade e potencializar contextos situacionais (SAAD, 2012). Por sua vez, os jogos recreativos são caracterizados como aqueles que possuem fins de recreação e podem estimular o desenvolvimento dos aspectos técnico-táticos (SAAD, 2012). 
Ressalta-se que, no decorrer do processo de desenvolvimento dos treinamentos, visouse respeitar a individualidade dos jovens, e a partir das respostas dos mesmos, da aprendizagem e do domínio dos objetivos que eram propostos, avançava-se para os próximos conteúdos ou ampliava-se o tempo de permanência nos mesmos para uma melhor apropriação.

\section{Percepções dos treinadores}

Para a descrição das percepções, os treinadores realizaram reuniões de discussão sobre temáticas relacionadas ao desenvolvimento do projeto, baseadas nas experiências, planejamentos e registros descritos posteriores às práticas realizadas. Nessas reuniões, cada treinador era responsável por registrar as suas percepções em planilhas organizadas no Microsoft Word, que posteriormente foram estruturadas conjuntamente para o relato final.

Nesse sentido, este estudo caracteriza-se como qualitativo, de caráter descritivo (DENZIN; LINCOLN, 2006), e configura-se como um relato de experiência por conferir voz aos educadores e proporcionar reflexões das ações realizadas, bem como percepções dos envolvidos no processo de implementação do projeto (NEIRA, 2017). O projeto de pesquisa foi aprovado no Comitê de Ética em Pesquisa com Seres Humanos de uma universidade pública brasileira (Parecer $n^{\circ}$ 2376990). Ressalta-se que, neste estudo, foi assegurado o anonimato da escola em que o projeto de extensão esportivo de basquetebol foi implementado.

Os treinadores (os primeiros cinco autores deste relato de experiência) que participam do projeto de extensão de iniciação ao basquetebol inserido na escola apontam as suas percepções relacionadas à estrutura e aos materiais para a realização do projeto, as suas percepções quanto à atuação como treinador, a relação com os jovens, as facilidades e as dificuldades encontradas neste processo, bem como os impactos percebidos nos jovens participantes e na comunidade.

\section{Estrutura e materiais}

Com relação ao ensino do basquetebol, segundo Marques e Ribeiro (2019), primeiramente há a necessidade de um espaço físico escolar estruturado. Achado semelhante no estudo de Collet et al., (2019), no qual os treinadores participantes do estudo enfatizaram a importância de ambientes estruturados para o desenvolvimento dos atletas. Além disso, parte dos treinadores destacaram que possuem grande número de recursos porque trabalham em escolas ou clubes particulares, mas a maioria mencionou a necessidade de melhores equipamentos e estrutura para realização dos treinamentos.

Diante do exposto, a infraestrutura inadequada parece se tornar fator limitante para o desenvolvimento do basquetebol no contexto escolar brasileiro, frisado pelo estudo de 
Volpato (2008). Ainda, observa-se, em muitos estudos, que para a realização das aulas de Educação Física, no geral, os professores têm relatado muitas dificuldades quanto à infraestrutura inadequada (DE OLIVEIRA, 1997; GASPARI et al., 2006; IMPOLCETTO; DARIDO, 2011). Entretanto, na respectiva escola, na qual se insere o projeto de extensão de iniciação ao basquetebol, a maioria dos treinadores aponta uma estrutura razoavelmente adequada para a realização do projeto de extensão.

Nesse sentido, a Treinadora 4 considera o espaço físico da escola apropriado, tendo em vista que apresenta um ginásio coberto, com duas tabelas de basquete, um espaço amplo, seguro e bem iluminado. Diferentemente, para o Treinador 1, não se conta com a melhor infraestrutura, mas apresenta condições básicas para que se possa ministrar o treino de forma segura e bem estruturada. Em contrapartida, o Treinador 2 aponta que a escola possui um ótimo espaço, porém, mal aproveitado, frisado também pelo Treinador 3, o qual relata que onde se tem o espaço de uma quadra poderia se ter mais duas no sentido transversal. Algo semelhante ao relatado no estudo de Pope e O'Sullivan (2003), onde o ginásio da escola no qual desenvolveram um estudo etnográfico apresentava seis tabelas, correspondendo a dois campos transversais e um campo longitudinal. Os autores observaram que, na maioria das vezes, os estudantes, nos seus horários livres, realizavam jogos reduzidos de $3 \times 3,4 \times 4$ ou algum jogo de lançamento em cada tabela, aproveitando de forma significativa o espaço do ginásio.

O Treinador 2 relata que os materiais para intervenção são suficientes para desenvolver uma boa prática, como na fala em destaque: “[...] as tabelas não têm a melhor qualidade, mas desempenham seu papel; e o material disponível permite a realização das atividades sem grandes problemas." Entretanto, a Treinadora 5 comenta que, em alguns momentos, sente-se falta de um ou outro material, porém, adapta-se com o que se tem à disposição: "À̀s vezes, precisamos de um tipo de material que não temos, mas a gente dá um jeito, se vira com o que tem, a gente busca adaptar pra realizar a atividade mesmo assim".

Marques e Ribeiro (2019) apresentaram o basquetebol em uma escola pública da cidade de Manaus para alunos do sétimo ano nas aulas de Educação Física e constataram que, apesar de severas limitações do contexto escolar, sem espaço físico apropriado, conseguiram efetivar a atividade. Assim, ainda que a escola do relato em foco conte com estrutura e materiais medianos para a prática, como apontou a maioria dos treinadores, é possível implementar a modalidade, adaptando-se à realidade do contexto.

\section{Atuação como treinador}

Quanto à atuação dos treinadores nos treinos da escola, a Treinadora 4, que atua na categoria sub 16 feminino, relata que os 4 treinadores desta categoria atuavam de forma segmentada no início do projeto, ou seja, os momentos do treino eram centrados em um treinador em específico, enquanto os outros, de forma acuada, aguardavam o seu momento, e vez ou outra interviam na atividade. Contudo, no decorrer do processo, a atuação dos 
treinadores tornou-se harmoniosa e integrada, e ao mesmo tempo que um sobressaia-se em uma atividade para conduzir o grupo de atletas, os outros atuavam em conjunto, participando, auxiliando e ensinando em prol de um melhor desenvolvimento das jovens. A treinadora 5 corrobora e reforça que atuar como treinadora em grupo trouxe muitos contributos para sua atuação profissional.

Para o Treinador 3, que atua na categoria sub 12 misto, a experiência prévia com a faixa etária facilitou o processo dos treinos tanto na comunicação com os jovens quanto na organização da atuação como um todo, como destacado no excerto a seguir: "Quando eu estava na graduação, tive a oportunidade de ser um dos treinadores de um projeto de iniciação esportiva no basquetebol, o que me proporcionou experiências positivas como treinador e me auxiliou na intervenção com o projeto de extensão atual". Para o Treinador 1, a experiência no treino de basquetebol permitiu vivenciar e refletir a atuação enquanto treinador através do planejamento e condução das atividades e destacou que o programa de extensão é uma via de mão dupla no sentido de gerar aprendizado para os jovens participantes e treinadores. Corroborando, o Treinador 2 relata que

\footnotetext{
"Para os alunos de graduação em Educação Física, a falta de espaços para o aprendizado prático é um obstáculo a mais na formação profissional. Ter a oportunidade de atuar em um contexto em que existe troca de aprendizado constante engrandece o ensino da universidade e nos dá uma bagagem extra de experiência para as oportunidades vindouras".
}

Nesse sentido, Campos e colaboradores (2016) reforçam os benefícios da prática extensionista, colaborando para a formação dos futuros profissionais na área; com o ensino, fornecendo espaço e tempo para estudos e vivências das disciplinas de graduação e com a dimensão da pesquisa, possibilitando formação técnico-científica aos acadêmicos da instituição.

Os benefícios da participação em projeto de extensão também são apontados no estudo de Gomes, Matthiesen e Ginciene (2011), os quais relatam sobre a experiência de atuação em um projeto de extensão de atletismo e descrevem que o projeto contribuiu para a formação profissional dos estagiários e bolsistas, responsáveis pela organização e implementação das atividades propostas. Por sua vez, De Oliveira, Lecardelli e Campagnollo (2019) também reforçam, em seu estudo, o valor da experiência possibilitado a um acadêmico em formação na implementação de um projeto de minibasquete, por meio do Programa Institucional de Bolsa de Iniciação à Docência (PIBID), com os alunos do $3^{\circ}$ ano do Ensino Fundamental. Por meio desta experiência, o acadêmico em formação pode conciliar à prática os ensinamentos aprendidos, como planejar, organizar e realizar aulas, enriquecendo, assim, a sua formação profissional.

\section{Relacionamento com os jovens participantes}

No que tange ao relacionamento com os jovens participantes do projeto na escola, todos os 5 treinadores apontam relações positivas com os jovens. O Treinador 1 
reforça que a boa relação com o grupo permitiu aproveitar os momentos de treinamento e ainda compartilhar as decisões dos conteúdos de treino com os jovens, como no trecho a seguir:

\begin{abstract}
“Acredito que o diálogo e a boa relação com o grupo permitiram-nos aproveitar ao máximo os momentos de treinamento. Apesar de os treinos serem planejados e conduzidos por nós, havia, de certa forma, uma negociação de como eles queriam aprender e se eles queriam aprender. Sempre procuramos manter os alunos autônomos".
\end{abstract}

Para o Treinador 3, um dos aspectos que expõe como consequência de um bom relacionamento com os participantes foi a sua quantidade, que se manteve do início ao fim do projeto, como destacado: "Era possível perceber, nas falas dos alunos, que eles estavam gostando daquele ambiente e faziam questão de estar lá; e isso, de certa forma, é muito gratificante, sabemos que tem associação com o relacionamento criado entre treinador e atletas". A Treinadora 4 destaca a importância do respeito mútuo entre os treinadores e os jovens, o que contribui para a formação de um ambiente saudável e agradável.

Ugrinowitsch e Barbanti (1999, p. 4) alertam que "Um técnico assume a responsabilidade de fazer qualquer coisa para que os jovens de seu time tenham uma experiência esportiva agradável e segura ao aprenderem as habilidades esportivas". Os autores Rose Junior e Tricoli (2005) reforçam que o objetivo é que a criança se sinta à vontade com a modalidade, que consiga conviver com ela do jeito que desejar. Desta maneira, os treinadores são responsáveis por construir um relacionamento saudável com os jovens, além de um ambiente seguro e agradável para a realização da modalidade esportiva.

A Treinadora 5 destaca que o relacionamento com as atletas é regido por respeito, confiança e possibilita uma conexão próxima e positiva entre todos, e no qual, muitas vezes, ela assume papel de amiga, conselheira e mãe: "Nós temos uma relação muito próxima com as meninas, construímos uma relação de confiança, a gente acaba sendo muito mais que treinadores nesse contexto". Achados semelhantes no estudo de Tozetto et al. (2020), no qual estudantes de Educação Física compreendem que o papel do treinador na abordagem do DPJ não se resume apenas ao papel de técnico que estrutura o treino e aprimora habilidades, mas também de amigo, que aconselha e acolhe; de educador, que forma valores e é exemplo; de líder, que motiva e é autocrítico; e de facilitador, que cria oportunidades e promove a modalidade.

Através das percepções relatadas pelos treinadores, percebe-se que atuam sempre em prol de uma comunicação aberta e valorizam relações positivas para a continuação e permanência dos jovens no projeto esportivo. Segundo Camiré et al. (2011), estabelecer relações significativas com os alunos/atletas é uma das estratégias para o desenvolvimento positivo deles, mas essas relações devem ser acompanhadas pela credibilidade do treinador, ou seja, os alunos precisam saber que o treinador tem os conhecimentos necessários para ensinar.

Cada um dos treinadores deste presente relato se relaciona de forma diferente com seus jogadores. Moen (2014) relata que qualquer relacionamento treinador/atleta é realmente um contexto específico, e para adaptar o comportamento do treinador às necessidades de cada 
atleta, torna-se necessário entender as necessidades do mesmo, sendo a comunicação um fator primordial neste processo. Os autores Shondell e Reynaud (2005) complementam que, além de uma boa comunicação, o treinador deve se importar, ser paciente, calmo, motivador e exigente com os jogadores. Além disso, deve encorajá-los e motivá-los em outras áreas da vida, ou seja, preocupando-se com o desenvolvimento integral do jogador. Desta forma, consequentemente será estabelecida uma relação positiva e significativa com os jovens.

\section{Facilidades}

Com relação às facilidades presentes na implementação do projeto de extensão no contexto escolar, o Treinador 1 destaca a possibilidade de aproximação do pesquisador com a prática profissional: "Essa aproximação nem sempre é presente no contexto da pós-graduação. Ter a oportunidade de sair do laboratório e entrar em uma quadra para ministrar aulas de basquete é um contributo muito grande para minha formação acadêmica e profissional." Além disso, destaca a oportunidade e liberdade para intervir no treino e aprender com os erros e acertos, e a dinâmica de 2 treinadores atuando juntos, o que facilita na condução dos treinamentos.

A Treinadora 5 reforça que atuar como treinadora quando se tem uma equipe de treinadores auxiliando facilita o desenvolvimento dos treinos e, ainda, consegue-se estar mais próximo de cada atleta, corrigindo, fornecendo atenção e dialogando. A Treinadora 4 complementa, relatando que a equipe grande de treinadores não sobrecarrega os integrantes responsáveis pela estruturação, planejamento e implementação dos treinos, conforme o excerto a seguir: "[...] mas essa questão de ter vários treinadores nos auxilia muito, pois um consegue cobrir o outro, dividimos as tarefas e isso torna mais fácil conciliar todas as demandas". Além disso, descreve que a frequência e a permanência dos jovens no projeto são facilitadas pelo fato de os treinos acontecerem no ginásio da escola. Ressalta, ainda, o fácil acesso à direção escolar para a resolução de problemas e apoio nas exigências encontradas.

Para o Treinador 2, a facilidade está relacionada aos jovens, ao apontar que o projeto se tornou um meio de transformação e oportunidade para os estudantes da escola: "O contexto onde está inserido (aos pés de uma comunidade) não convida os alunos ao seu crescimento e, quanto a isso, vejo o nosso projeto como um elemento transformador para as crianças." Dória e Tubino (2006) testificam a importância de atividades esportivas na vida dos praticantes, ainda mais quando se refere a crianças e adolescentes em vulnerabilidade social. Consequentemente, culminando em benefícios técnicos, táticos, físicos, psicológicos e sociais, além de promover um ambiente de diversificação, inclusão, cooperação e autonomia (PAES; BALBINO, 2005).

Outras facilidades são apontadas pelo Treinador 3, como a localização da escola, por estar próxima à universidade, facilitando a ida e o retorno ao local de treinamento, fato também destacado no estudo de Barbosa e Araújo (2018), e o fomento à conexão entre a escola e o contexto universitário, tanto para os treinadores quanto para os jovens participantes, pois 
também se realizam treinos mensalmente nos espaços universitários para estes jovens, oportunizando a aproximação com este contexto.

A importância desta conexão entre a escola e a universidade também é reforçada no estudo de Arruda-Barbosa e colaboradores (2019), o qual tinha como objetivo integrar e divulgar os cursos de saúde da Universidade Estadual de Roraima (UERR), por meio de projeto de extensão, com foco em estudantes que estão concluindo o ensino médio ou cursando cursinhos pré-vestibulares. Desta maneira, a universidade pode exercer parte de seu papel social de se aproximar da comunidade.

\section{Dificuldades}

Com relação às dificuldades encontradas pelos treinadores, a Treinadora 4 elenca a sobrecarga acadêmica dos treinadores, como todos estão inseridos na graduação ou pósgraduação, em alguns momentos as demandas acadêmicas impossibilitam a presença de um ou outro treinador no contexto do treino, além de limitarem o tempo para planejamento das atividades. E complementa: "Principalmente no meio e final de semestre letivo na graduação, as tarefas se acumulam muito, e isso sobrecarrega e muitas vezes até impede a participação em um ou outro treino $[\ldots] "$ ".

Para os Treinadores 1 e 2, a maior dificuldade é manter os jovens em alto nível de engajamento e motivação em todos os treinos. Achado semelhante no estudo de Tozetto et al. (2019), no qual os treinadores comentam sobre as barreiras para motivar os novos atletas para a prática e, ainda, aliar a preparação esportiva com a formação cidadã. Além disso, também apontam desafios para gerir a prática, como a falta de recursos, a gestão esportiva e falta de tempo, bem como desafios relacionados à carreira, e alguns pensam no abandono da profissão e apresentam dificuldade em progredir.

Para a Treinadora 5, os dias de chuva ocasionam muitas dificuldades, além do fato de reduzir o número de jovens no treino, além de que o número de goteiras presentes no ginásio atrapalha ou impede a realização das atividades. A Treinadora 4 reforça que dias de chuva põem em risco tanto os jovens quanto os treinadores, pelo fato de que a acústica, quando o volume de chuva é intenso, faz com que os treinadores precisem elevar muito o tom de voz para explicar as atividades: "Quando está chovendo muito forte, além das goteiras na quadra, a acústica obriga a nós, professores, a falar muito alto, a depender da chuva até gritando, e esse aumento no tom de voz é muito ruim para nós com o passar do tempo".

No estudo de Fernandes (2018) e de Barbosa (2018), também se relatam as dificuldades ocasionadas pela chuva, mas Barbosa (2018) alerta que os professores devem estar preparados para quaisquer adversidades e utilizar estratégias para superá-las.

Outra barreira presente na implementação do projeto é a altura das tabelas não adaptada para a categoria sub 12 misto, apontado pelo Treinador 3: "Uma das poucas barreiras é a altura 
da tabela, fator que interfere na aprendizagem dos alunos e muitas vezes desmotiva os mesmos a arremessar na cesta durante as atividades que requeriam esse movimento". Os autores Marramarco, Marramarco e Gaya (2014) destacam que essa faixa etária apresenta algumas necessidades, como uma tabela de altura reduzida para a execução do arremesso à cesta e uma bola mais leve para a execução das habilidades técnicas esportivas. Por meio de Marques (2015), isso é reforçado, pois o estudo, que tinha como objetivo saber se a introdução de um constrangimento da tarefa, altura do cesto, modificaria ou não o sucesso do sujeito $(11,58 \pm$ 0,52 anos de idade) na execução dos movimentos, mostrou que os sujeitos alcançaram melhores resultados na tabela de minibasquete, além disso, verificou-se que existem diferenças estatisticamente significativas que permitem concluir que a altura do cesto tem um efeito significativo no desempenho motor qualitativo. Nesse sentido, sabendo que o principal protagonista é a criança, a prática desportiva deve-se alicerçar "em seus diferentes aspectos: motor, social, psicológico, filosófico e intelectual” (PAES, 2006, p. 224), visando promover uma prática prazerosa aos participantes com desenvolvimento das habilidades do basquetebol.

\section{Impacto do projeto sobre os jovens participantes e sobre a comunidade}

Segundo as percepções dos treinadores, o projeto de extensão esportivo impactou de forma positiva os jovens, não apenas dentro da quadra, mas para outras áreas da vida, além de refletir efeitos também sobre a própria comunidade escolar. Segundo a Treinadora 4, o projeto fomentou a inclusão dos estudantes, promoveu um sentimento de pertencimento exemplificado pelo momento em que usam a camiseta do projeto e sentem-se parte dele, quando anseiam por mais treinos e quando na escola são reconhecidos por serem praticantes da modalidade. Corroborando essa percepção, o Treinador 1 e a Treinadora 5 reforçam que, por meio do projeto, os jovens se sentiram acolhidos e incluídos. Da mesma maneira, o Treinador 2 aponta a inclusão como um grande impacto na vida dos jovens, principalmente quando se refere a um projeto que faz parte da universidade, por mais que a localização fosse próxima, não existia e nem se fomentava uma conexão entre estes dois contextos, algo frisado também pelo Treinador 1.

Além do sentimento de pertencimento e da conexão entre escola e universidade, a Treinadora 4 aponta melhoras nas relações interpessoais na própria escola, pois até então, as estudantes mais velhas não eram próximas das mais novas, contudo, o projeto promoveu aproximação entre elas, o que, segundo o Treinador 1 e a Treinadora 5, oportunizou a formação de novas amizades entre estudantes de idades distintas. Ainda, pode-se destacar o desenvolvimento de valores e atitudes, como o respeito e empatia e a promoção de um estilo de vida mais ativo e saudável, referidos pelo Treinador 1, consequências também destacadas no estudo de Barbosa e Araújo (2018). 
O projeto também despertou o gosto dos estudantes pela modalidade esportiva, que segundo o Treinador 3, contribuiu para que os jovens praticassem a modalidade em diversos espaços (em casa ou em praças públicas) e momentos para além das aulas de Educação Física.

$\mathrm{O}$ encantamento dos jovens pela modalidade também é relatado pelo Treinador 2 e pela Treinadora 5, a qual ainda destaca que esse sentimento despertou nas jovens participantes o desejo de realizar melhorias no ginásio esportivo, visando um ambiente mais agradável e seguro para a prática do basquetebol. Logo, junto à gestão escolar, conquistaram lixeiras e bebedouro para o ginásio, o que antes eram ausentes.

Os treinadores também percebem impactos do projeto na comunidade, assim como os coordenadores de um projeto de extensão no estudo de Capistrano et al. (2020), o qual relata que o projeto esportivo teve um alcance além do esperado, justamente por buscar atender as necessidades do contexto em que estavam inseridos. Para o Treinador 2, a aproximação da escola com a Universidade permitiu uma melhor visibilidade do trabalho acadêmico. Além disso, a Treinadora 4 relata o reconhecimento e a valorização e integração do projeto nas atividades da escola. Algo reforçado pela Treinadora 5, que frisa que, nos dias de entrega de boletim, a gestão escolar solicita a presença dos treinadores e das atividades do projeto, conforme o excerto a seguir: "Penso que algo muito bacana é que a escola nos procura pra participar, pra estar presente na entrega dos boletins, pra gente realizar as atividades de basquetebol, pra mim isso demonstra que reconhecem o nosso valor, que querem a gente cada vez mais perto dessa comunidade".

Outro impacto positivo destacado pela Treinadora 5 foi a percepção dos pais das participantes, que relataram que, com o projeto, as jovens apresentaram mais organização, dedicação e responsabilidade em suas atividades, se tornaram mais comunicativas e fortaleceram um grupo de amizades, também frisado pela Treinadora 4. O Treinador 1 também cita os pais: “[...] a comunidade, que é formada pelos pais dos alunos, sente uma leve mudança de cultura e preferência pelo basquete por parte de seus filhos." Segundo o Treinador 3 da categoria sub 12, a presença dos pais é muito marcante nos treinos, nos quais, muitas vezes, querem auxiliar os filhos. Este treinador cita um momento que reflete o apoio e envolvimento dos pais, quando foram registrar um treino com todos os participantes, utilizando a camiseta do projeto, e todos os pais entraram na quadra para tirar foto dos filhos com o uniforme. Segundo o treinador, por mais que parecesse um gesto simples, representou o retrato do engajamento dos pais com a prática dos filhos.

\section{Considerações finais}

A inserção de um projeto de extensão de iniciação ao basquetebol em contexto escolar desempenha um importante papel na vida dos praticantes, facilitando o desenvolvimento da sociabilidade e das relações interpessoais. Para os treinadores que estão em processo de 
formação inicial e formação de pós-graduação, participar deste projeto propicia experiências e desafios que têm contribuído efetivamente para a formação profissional.

Neste artigo, os treinadores relataram suas percepções quanto à implementação do projeto de extensão em contexto escolar. Segundo as percepções dos treinadores, a escola apresenta materiais e estrutura medianas para a implementação do projeto. Quanto à atuação como treinador, os treinadores descrevem que esta experiência contribuiu de forma significativa para a formação profissional. No que se refere ao relacionamento com os jovens participantes, todos os treinadores afirmam possuir relações positivas, as quais facilitam o desenvolvimento do projeto.

Dentre as facilidades observadas pelos treinadores, citam-se algumas, como: o grande número de treinadores, a localização da escola ser próxima à universidade e a oportunidade de experienciar na prática o que se aprende na teoria. Por sua vez, algumas barreiras apontadas pelos treinadores são: dias de chuva, por acarretarem goteiras; tabelas altas demais para a categoria do sub 12, e a necessidade de manter os jovens em alto nível de engajamento e motivação em todos os treinos. Mesmo diante das dificuldades apontadas, percebem impactos positivos sobre os jovens participantes e sobre a comunidade.

Portanto, relatar a experiência deste projeto esportivo no âmbito escolar possibilita instigar a implementação de futuros projetos de extensão esportivo em contexto escolar, promovendo aproximação entre os dois contextos - universidade e escola - visando o desenvolvimento de jovens por meio do esporte, bem como o desenvolvimento e aperfeiçoamento profissional de acadêmicos e pós-graduandos em Educação Física, além de informar sobre os meios para a realização de projetos e as dificuldades que podem ser encontradas no processo.

O presente estudo foi realizado com o apoio da Coordenação de Aperfeiçoamento de Pessoal de Nível Superior (CAPES), sob código de financiamento 001 e, também, com o apoio do Conselho Nacional de Desenvolvimento Científico e Tecnológico (CNPQ).

\section{Referências}

ALMEIDA, M. B. Basquetebol iniciação. 2. ed. Rio de Janeiro: Sprint, 2000.

ARRUDA-BARBOSA, L.; SALES, M. C.; SOUZA, I. L. L., GONDIM-SALES, A. F.; SILVA, G. C. N., LIMA-JÚNIOR, M. M. Extensão como ferramenta de aproximação da universidade com o ensino médio. Cadernos de Pesquisa, São Paulo, v. 49, n. 174, p. 316327, 2019. Disponível em: https://doi.org/10.1590/198053146465. Acesso em: 10 jan. 2020.

BARBOSA, J. S.; DE ARAÚJO, M. A. L. Cultura (corporal), educação e esporte-a formação cidadã de jovens no sertão baiano. Revista Conexão UEPG, Ponta Grossa, v. 15, n. 1, p. 083-091, 2019. Disponível: https://doi.org/10.5212/Rev.Conexao.v.15.i1.0011. Acesso em: 25 mar. 2020. 
BARBOZA, G. O. Influência da arquitetura escolar nas aulas de Educação Física: estratégias utilizadas para contornar as adversidades arquitetônicas e climáticas. $50 \mathrm{f}$. Monografia de Conclusão de Curso. Universidade Federal do Rio Grande do Sul. Escola de Educação Física, Fisioterapia e Dança, Porto Alegre-RS, 2018.

CAMIRÉ, M.; FORNERIS, T.; TRUDEL, P.; BERNARD, D. Strategies for helping coaches facilitate positive youth development through sport. Journal of sport psychology in action, v. 2, n. 2, p. 92-99, 2011. Disponível em: https://doi.org/10.1080/21520704.2011.584246. Acesso em: 10 jan. 2020.

CAMPOS, I. S. L. et al. Esportes de combate e extensão universitária: Inserções com o ensino e a pesquisa. Revista Conexão UEPG, Ponta Grossa, v. 12, n. 2, p. 352-363, 2016. Disponível em: https://doi.org/10.5212/Rev.Conexao.v.12.i2.0015. Acesso em: 10 jun. 2020.

CAPISTRANO, E. O.; DANTAS, M. G. S.; ARCANJO, M. S.; MEDEIROS, J. V. M. Lições aprendidas em projetos de extensão esportivos em uma Instituição Federal de Ensino. Revista de Gestão e Projetos (GeP), v. 11, n. 1, p. 111-129, 2020. Disponível em: https://doi.org/10.5585/gep.v115i1.14542xx. Acesso em: 11 jan. 2020.

COLLET, C.; TOZETTO, A. V. B.; IHA, T; NASCIMENTO, J. V. FALCÃO, W.; MILISTETD, M. Dynamic Elements of Sports Development: Perceptions of Basketball Coaches. Revista de Psicología del Deporte, Almería E Barcelona, v. 28, n. 3, p. 79-85, 2019.

CÔTÉ, J. Pathways to expertise in team sport. In: NASCIMENTO, J. V.; RAMOS, V.; TAVARES, F. (Orgs.). Jogos Desportivos: formação e investigação. Florianópolis: UDESC, 2013. p. 59-77.

DAMON, W. What is positive youth development?. The Annals of the American Academy of Political and Social Science, v. 591, n. 1, p. 13-24, 2004.

DENZIN, N. K.; LINCOLN, Y. S. O planejamento da pesquisa qualitativa: teorias e abordagens. In: O planejamento da pesquisa qualitativa: teorias e abordagens. 2006. p. $432-432$

DE OLIVEIRA, A. A. B. Metodologias emergentes no ensino da educação física. Journal of Physical Education, Maringá, v. 8, n. 1, p. 21-27, 1997. Disponível em: http://periodicos.uem.br/ojs/index.php/RevEducFis/article/view/3868. Acesso em: 15 jan. 2020.

DE OLIVEIRA, S. R.; LECARDELLI, A. P.; CAMPAGNOLLO, Â. M. O minibasquete na Educação Física Escolar. Anuário Pesquisa e Extensão Unoesc Chapecó, Chapecó, v. 4, p. e23626-e23626, 2019. 
DORIA, C.; TUBINO, M. J. G. Avaliação da busca da cidadania pelo Projeto Olímpico da Mangueira. Ensaio: Avaliação e Políticas Públicas em Educação, Rio de Janeiro, v. 14, n. 50, p. 77-90, 2006.

ESPERANÇA, J. L.; DIAS, C.; BRUSTAD, R. J.; FONSECA, A. M.. Desenvolvimento positivo dos jovens: Estudo exploratório realizado com estudantes portugueses. Análise Psicológica, Lisboa, v. 36, n. 4, p. 427-437, 2018.

FERNANDES, E. V. C.. Iniciação desportiva na educação física escolar: o ensino da cultura esportiva com uma abordagem inclusiva. In: CORRÊA, H. R.; FIORUCCI, R.; PAIXÃO, S. V. (Orgs.). Currículo Inovador: Experiências didáticas no IFPR Jacarezinho. Jacarezinho. Curitiba: Editora IFPR, 2018. p. 117-126.

GAION, P. A.; MILISTETD, M.; SANTOS, F.; CONTREIRA, A.; ARANTES, L.;

CARUZZO, N. M. Coaching Positive Youth Development in Brazil: Recommendations for Coach Education Programs. International Sport Coaching Journal, v. 7, n. 1, p. 1-7, 2020.

GALATTI, L. R. Esporte e clube sócio-esportivo: percurso, contextos e perspectivas a partir de um estudo de caso em clube esportivo espanhol. 292f. Tese de Doutorado. Universidade Federal de Campinas, Curso de Educação Física, Campinas, 2010.

GALATTI, L. R.; SERRANO, P.; SEOANE, A. M.; PAES, R. R.. Pedagogia do esporte e basquetebol: aspectos metodológicos para o desenvolvimento motor e técnico do atleta em formação. Revista Arquivos em Movimento, Rio de Janeiro, v. 8, n. 2 , p.79-93, 2012.

GASPARI, T. C.; SOUZA JUNIOR, O.; MACIEL, V.; IMPOLCETTO, F.; VENANCIO, L.; ROSÁRIO, L. F.; THOMAAZO, A. D.; DARIDO, S. C. A realidade dos professores de Educação Física na escola: suas dificuldades e sugestões. Revista Mineira de Educação Física, Viçosa, v. 14, n. 1, p. 109-137, 2006.

GOMES, A.; MATTHIESEN, S.; GINCIENE, G. Atletismo para crianças e jovens: um projeto de extensão universitária. Revista Ciência em Extensão, São Paulo, v. 7, n. 1, p. 6$15,2011$.

IMPOLCETTO, F.; DARIDO, S. C. Uma introdução ao livro. In: DARIDO, S. C. (Org.). Educação Física Escolar: compartilhando experiências. São Paulo: Phorte, 2011. p. 15-21.

LUCKESI, C. C. Avaliação da aprendizagem escolar. 20 ed. São Paulo: Cortez, 2009.

MACHADO, G. V.; GALATTI, L. R.; PAES, R. R. Pedagogia do esporte e projetos sociais: interlocuções sobre a prática pedagógica. Movimento, Rio Grande do Sul, v. 21, n. 2, p. 405-418, 2015. Disponível em: https://doi.org/10.22456/1982-8918.48275. Acesso em: 20 de fev. 2020. 
MARQUES, M.; RIBEIRO, N.; COLARES, J. O ensino do basquetebol e o espaço físico em questão: um relato de experiência a partir de uma escola pública do norte. Motrivivência, Florianópolis, v. 31, n. 58, 2019. Disponível em: https://periodicos.ufsc.br/index.php/motrivivencia/article/view/56328. Acesso em: 29 jan. 2020.

MARQUES, R. C. A. Efeitos da modificação da altura do cesto de basquetebol no nível de desempenho motor do lance livre. 117f. Dissertação de Mestrado. Escola Superior de Educação | Politécnico de Coimbra. Departamento de Educação da Escola Superior de Educação de Coimbra, Coimbra, 2015.

MARRAMARCO, G. T.; MARRAMARCO, C. A.; GAYA, A. C. A. Proposição de um instrumento de avaliação de habilidades técnicas de basquetebol para crianças de 10 e 11 anos. DO CORPO: ciências e artes, v. 4, n. 1, p.1-11, 2014.

MOEN, F. The coach-athlete relationship and expectations. International Journal of Humanities and Social Science, v. 4, n. 11, p. 29-40, 2014.

NEIRA, M. G. Análise e produção de relatos de experiência da educação física cultural: uma alternativa para a formação de professores. Textos FCC, São Paulo, v. 53, p. 53-103, 2017. Disponível em: http://publicacoes.fcc.org.br/ojs/index.php/textosfcc/article/viewFile/5552/3586. Acessado em: 25 ago. 2020.

NOGUEIRA, V. A.; FARIAS, U. S.; MALDONADO, D. T. Práticas Pedagógicas inovadoras nas aulas de Educação Física Escolar: indícios de mudanças. 2. ed. Curitiba: CRV, 2017.

PAES, R. R. Pedagogia do esporte: especialização esportiva precoce. In: GO, T.; BENTO, J. O.; PETERSEN, R. D. S. Pedagogia do desporto. Rio de Janeiro: Guanabara Koogan. v.1, 2006. p. 219-226.

PAES, R. R.; BALBINO, H. F. Processo de ensino e aprendizagem do basquetebol: perspectivas pedagógicas. In: DE ROSE JR, D.; TRICOLI, V. (Orgs.). Basquetebol: uma visão integrada entre ciência e prática. 1 ed. Barueri: Manole, 2005.

PINTO, F. M.; COLOMBI, G. A conjuntura da EBM Beatriz de Souza Brito: formação docente e Educação Física. Cadernos de Formação RBCE, Brasília, v. 4, n.1, p. 9-12, 2013.

POPE, C; O'SULLIVAN, M. Darwinism in the gym. Journal of teaching in Physical Education, v.22, n.3, p.311-327, 2003. 
RAMOS, A. M.; NEVES, R. L. R. A iniciação esportiva e a especialização precoce à luz da teoria da complexidade-notas introdutórias. Pensar a Prática, Goiânia, v. 11, n. 1, p. 1-8, 2008.

RINK, J. Teaching physical education for learning. St. Louis: Mosby, 1993.

ROSE JUNIOR, D.; TRICOLI, V. Basquetebol: uma visão integrada entre ciência e prática. Barueri, SP: Manole, 2005.

RUBIO, K. O imaginário da derrota no esporte contemporâneo. Psicologia \& Sociedade, Porto Alegre, v. 18, n. 1, p. 86-91, 2006.

SAAD, M. A. A formação técnico-tática de jogadores de futsal nas categorias sub-13 e sub-15: análise do processo de ensino-aprendizagem-treinamento. 164f. Tese de Doutorado. Universidade Federal de Santa Catarina, Centro de Desportos, Programa de Pós-Graduação em Educação Física, Florianópolis, 2012.

SHONDELL, D.; REYNAUD, C. A bíblia do treinador de voleibol. Porto Alegre: Artmed, 2005.

SILVA, O. M.; SILVA, C. A. F. Desenho da rede de um projeto esportivo social: atores, representações e significados. Revista Brasileira de Educação Física e Esporte, São Paulo, v. 28, n. 3, p. 415-428, 2014. Disponível em: http://dx.doi.org/10.1590/180755092014000300415. Acesso em: 10 dez. 2020.

TOZETTO, A. B. MILISTETD, M.; COLLET, C., IHA, T.; ANELLO, J.; NASCIMENTO, J. V. Treinadores de basquetebol: os desafios da prática na formação esportiva de jovens. Cuadernos de Psicología del Deporte, Murcia, v. 19, n. 1, p.291-301, 2019.

TOZETTO, A. B.; PALHETA, C. E.; BRASIL, V. Z.; SALLES, W.N.; MILISTETD, M. A concepção de estudantes de Educação Física sobre a importância do esporte e os papéis do treinador no desenvolvimento positivo de jovens. Coleção Pesquisa em Educação Física, Jundiai, v. 19, n. 2, 2020.

UGRINOWITSCH, C; BARBANTI, V. J. Ensinando voleibol para jovens. São Paulo: Editora Manole LTDA, 1999.

VOLPATO, R. D. Propostas pedagógicas a partir da mídia para o conteúdo basquetebol. 88f. Trabalho de Conclusão de Curso. Universidade do Extremo Sul Catarinense, Faculdade de Educação Física, Criciúma, SC, 2008. 